\title{
The Preferred Orientation of the Ferrous Sulfide Scale on Pure Iron at $700^{\circ} \mathrm{C}$
}

\author{
By Toshio Narita* and Keizo Nishida*
}

\begin{abstract}
The preferred orientation and its variation with sulfur pressure were observed in the course of the study on the sulfurization of pure iron at $700^{\circ} \mathrm{C}$. Further, SEM observations revealed the characteristic variation of the surface morphology of the scale with sulfur pressure.

The preferred orientation of the grown scale changed with sulfur pressure and the orientation differences were quantitatively determined by means of $\mathrm{X}$-ray pole figures.

By using the diffusion theory as well as the present observations the effect of the preferred orientation of the scale on the overall corrosion rates was disclosed.

The calculated value of $1 / n$ as a measure of the pressure dependence of the corrosion rates is about $1 / 5.7$. This value suggests that there is no interaction between vacancies and positive holes in the ferrous sulfide at $700^{\circ} \mathrm{C}$. The similar conclusion was obtained from the relationships between vacancy concentration and sulfur activity determined previously by several authors.
\end{abstract}

(Received January 22, 1973)

\section{Introduction}

In a previous paper ${ }^{(1)}$, it was reported that the preferred orientation of the ferrous sulfide scale changed during the corrosion of pure iron in sulfur vapor under the various corrosion conditions of temperature and sulfur pressure, and that the slopes of the double logarithmic presentations of corrosion rate constant and sulfur pressure varied from 1/3.5 to 1/5.7. From these results and other observations it has been pointed out that the considerations of the lattice defects from this kind of investigation will lead to a erroneous reasoning because of ignoring the effect of the preferred orientation on the scaling rate.

As Birchenall indicated from the results of his tracer diffusion investigation ${ }^{(2)}$ in the single crystal of the ferrous sulfide the self-diffusivity of iron atoms along the c-axis is greater than that along the a-axis. Moreover, the self-diffusivity of sulfur atoms is negligibly small. Thus, the variation in the preferred orientation of the ferrous sulfide scale gives rise to a considerable influence on the scaling rate of pure iron, because the growth rate of the ferrous sulfide formed on pure iron is controlled by the outward migration of iron atoms through the scale.

In the present report, the preferred orientation of the scale was determined quantitatively by use of the pole figure technique in order to find the effect of the orientation on the sulfurization rate of pure iron. Further, from this measurement the true effect of the sulfur pressure on the scaling rate was deduced and also the defect structures in the ferrous sulfide were discussed.

\section{Experimental}

The test pieces of pure iron and sulfur, the corrosion

* Metals Research Institute, Faculty of Engineering, Hokkaido University, Sapporo 060, Japan. apparatus, and the experimental technique used in this investigation are the same as those in the previous $\operatorname{paper}^{(1)}$.

All the scales formed were first examined on their surface by means of X-ray diffraction and SEM observation, then preferred orientations of the ferrous sulfide scale were determined by use of an X-ray.pole figure analyzer. Here, the surface of the scale was polished slightly with \#1000 emery paper. The pole figures of the surface were directly shown as bright spots on the Braun tube of this analyzer. The conditions of the X-ray diffractometer and the X-ray pole figure analyzer are as follows: (1) X-ray diffractometer: $\mathrm{Cr}-\mathrm{K} \alpha$ ray filtered with $V$-foil, $30 \mathrm{kV} ; 10 \mathrm{~mA}$. Slit: $1^{\circ}-0.2 \mathrm{~mm}-1^{\circ}$. Scanning speed of the goniometer: $1 \% \mathrm{~min}$. Chart speed: $1 \mathrm{~cm} / \mathrm{min}$. Time constant: 2 . (2) $\mathrm{X}$-ray pole figure analyzer: $\mathrm{Co}-\mathrm{K}$ ray without filter, $30 \mathrm{kV} ; 10 \mathrm{~mA}$. Movement of sample: $10 \% \mathrm{~min}$ around $\alpha$-axis and $20 \mathrm{rpm}$ around $\beta$-axis. Measuring plane: (004) plane, i.e., $2 \theta=78.1^{\circ}$.

\section{Results}

X-ray diffraction patterns from the surface of the ferrous sulfide scale formed on pure iron at $700^{\circ} \mathrm{C}$ under various sulfur pressures are shown in Fig. 1, in which the indices of the diffraction peaks were determined as the pyrrhotite which has a $h c p$ structure with lattice parameters: $a=3.44 \AA$ and $c=5.59 \AA$. The two small peaks observed at high diffraction angles obtained under $P_{\mathrm{S}_{2}}=760 \mathrm{mmHg}$ were those from the $\mathrm{Fe}_{7} \mathrm{~S}_{8}$ phase which has the $h c p$ structure with lattice constants, $a=6.87 \AA$ and $c=22.4 \AA$, although the latter indices shown in the figure are not fully satisfied. Only the patterns from $(00 l)$ planes of the pyrrhotite and $\mathrm{Fe}_{7} \mathrm{~S}_{8}$ phases are found under $P_{\mathrm{S}_{2}}=760 \mathrm{mmHg}$, while those from the $(10 l)$ planes are found under $P_{\mathrm{S}_{2}}=76 \mathrm{mmHg}$, and also those of the (101) and (102) planes under $P_{\mathrm{S}_{2}}=7.6 \mathrm{mmHg}$. 


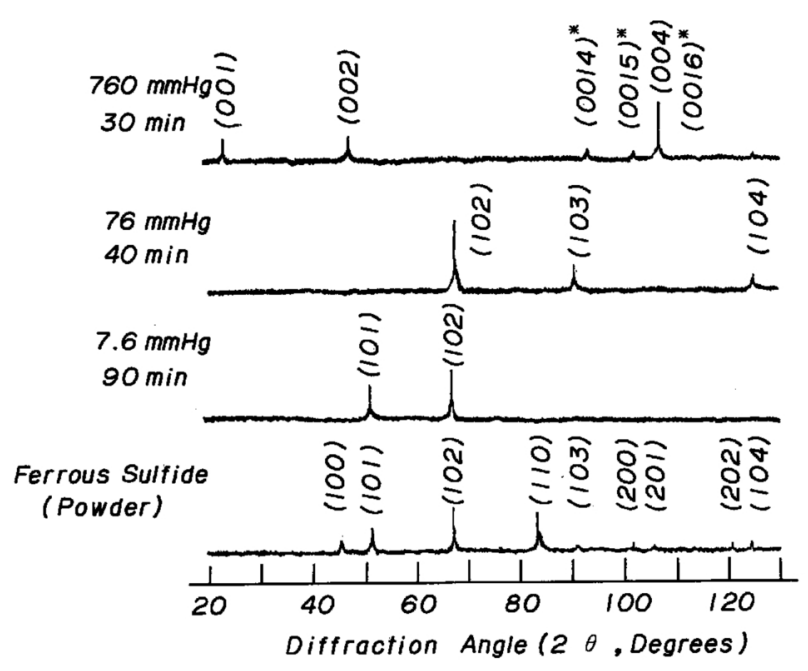

Fig. $1 \mathrm{X}$-ray diffraction patterns from the surface of ferrous sulfide scale formed on pure iron at $700^{\circ} \mathrm{C}$ under various sulfur pressures, where * shows the patterns from the $\mathrm{Fe}_{7} \mathrm{~S}_{8}$ phase.
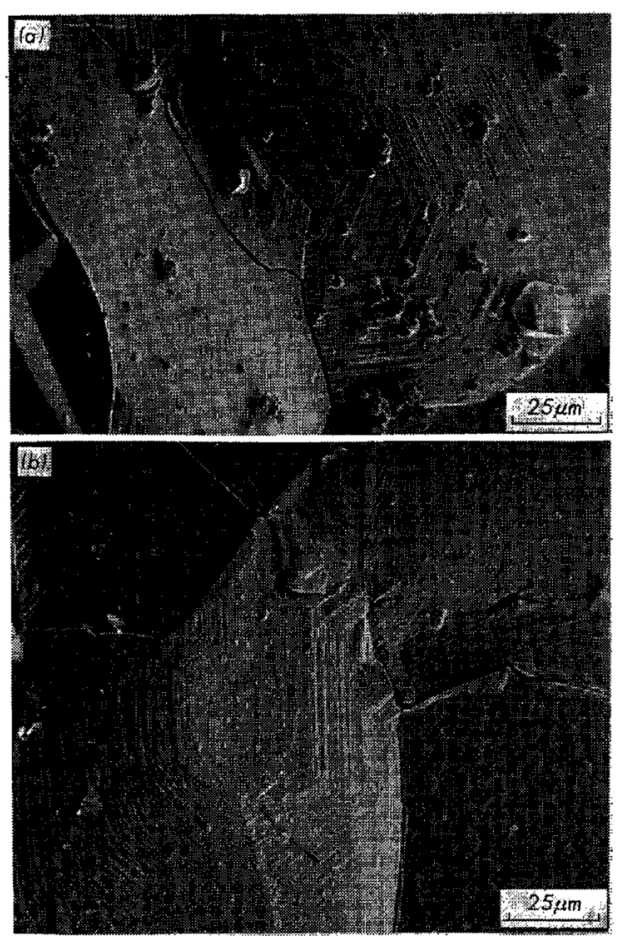

Photo. 1 Surface microstructures of the scale formed at $700^{\circ} \mathrm{C}$ under higher sulfur pressures, showing an intricated steplike crystal growth: (a) $760 \mathrm{mmHg}, 30 \mathrm{~min}$ and (b) $500 \mathrm{mmHg}$, $35 \mathrm{~min}$.

Photographs 1 and 2 show the surface microstructures observed by use of the SEM, indicating the change from intricated-step structures to more flat ones with decreasing of sulfur pressure. The observed results are very similar to those obtained at $800^{\circ} \mathrm{C}^{(1)}$.

The pole figures from the surfaces of the scales are shown in Fig. 2. Changes in relative intensity with various $\alpha$ 's are shown in Fig. 3. Here, the spot observed at the center of the figure corresponds to the patterns from the $(00 l)$ planes, that is, the c-axis of the ferrous sulfide crystal is considered to be perpendicular to the surface.
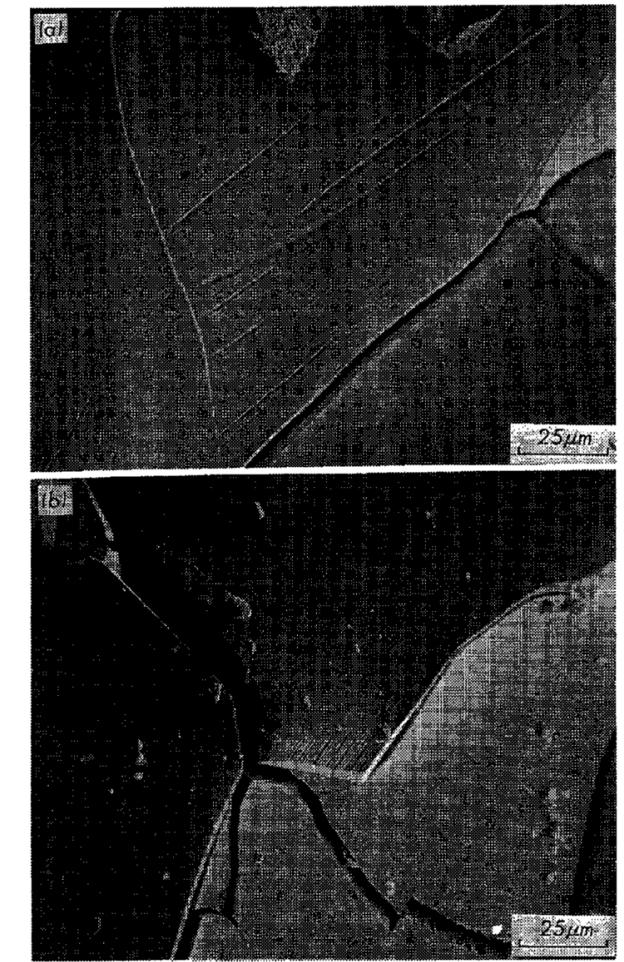

Photo. 2 Surface microstructures of the scale formed at $700^{\circ} \mathrm{C}$ under lower sulfur pressures, showing a flat surface: (a) $76 \mathrm{mmHg}, 40$ min and (b) $7.6 \mathrm{mmHg}, 90 \mathrm{~min}$.

Under $\mathrm{P}_{\mathrm{S}_{2}}=760 \mathrm{mmHg}$ the diffraction spots are all concentrated in the vicinity of the center within about 6 degrees. Therefore, it is suggested that every crystal grain arranges the c-axis almost perpendicular to the substrate surface, while under $P_{\mathrm{S}_{2}}=76 \mathrm{mmHg}$ the spots are scattered on a circle with some width. Furthermore, under $P_{\mathrm{S}_{2}}=7.6 \mathrm{mmHg}$ the scattering of the spots is more prominent. Also, the X-ray relative intensity around the $\alpha$-axis shows a similar behavior to those of the pole figures.

\section{Discussion}

The growth of the ferrous sulfide under the conditions of the present investigation was found to have the following characteristics: (1) The test piece used is pure polycrystalline iron and the grown scale is also made of the polycrystalline ferrous sulfide. (2) In the range of the sulfurization obeying a parabolic rate law each crystal grain of the scale showed a similar preferred orientation. (3) The preferred orientation changed with sulfur pressure and temperature. (4) The so-called inner layer containing many small voids is formed between the iron substrate and the porefree outer layer which constitute most parts of the scale. (5) The epitaxial relationship between crystals of the iron substrate and those of the thick outer layer is not maintained.

It has been discussed in detail in the previous paper $^{(1)}$ how the crystals randomly formed in the initial stage of sulfurization could change to have the same preferred orientation. In this report the effect of the preferred orientation of the scale on the overall 


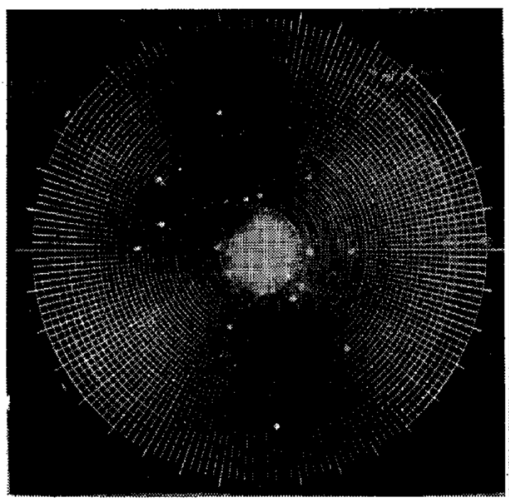

$760 \mathrm{mmHg}$ $30 \mathrm{~min}$

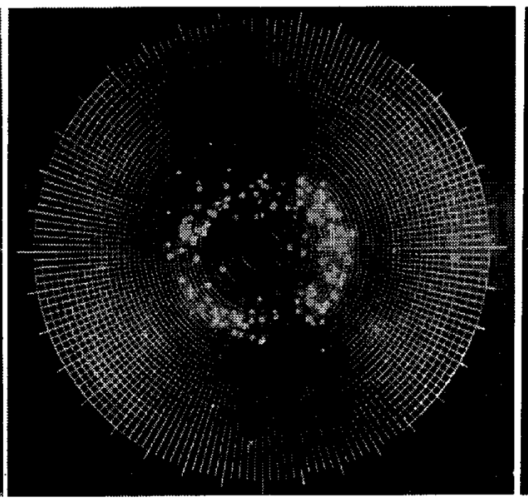

$76 \mathrm{mmHg}$ $40 \mathrm{~min}$

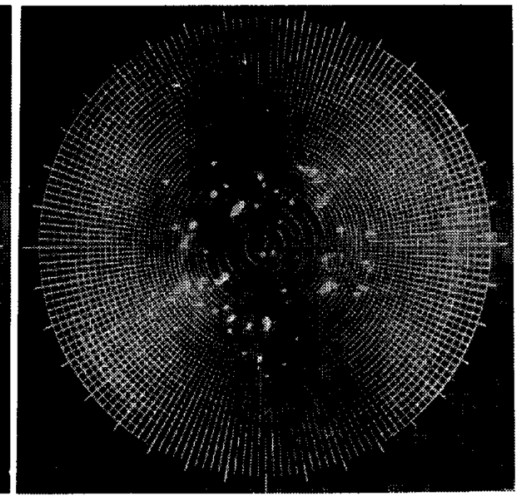

$7.6 \mathrm{mmHg}$

$90 \mathrm{~min}$

Fig. 2 Pole figures photoed from the scale surface formed at $700^{\circ} \mathrm{C}$ under various sulfur pressures, where the center of a Wulf's net corresponds to (004).

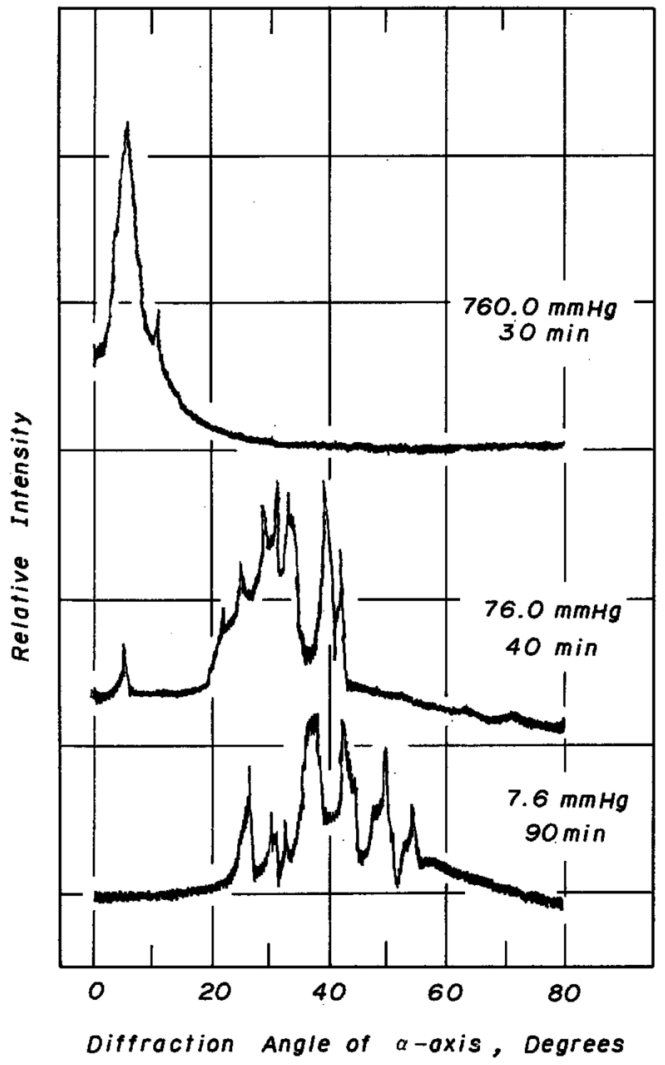

Fig. 3 Variation of X-ray intensity with the change in the angle of $\alpha$-axis.

corrosion rate is considered by using the diffusion theory of an anisotropic crystal, since the corrosion rate is controlled by the diffusion process of iron atoms in the outer layer of the scale.

Since the crystal of the ferrous sulfide has an anisotropy for the iron diffusion, the self-diffusivity of iron atoms along any direction of the crystal is given by the following equation ${ }^{(3)}$ :

$$
D_{\mathrm{Fe}}^{*}(\theta)=D_{\mathrm{Fe}(\mathrm{c})}^{*} \cdot \cos ^{2} \theta+D_{\mathrm{Fe}(\mathrm{a})}^{*} \cdot \sin ^{2} \theta
$$

where $\theta$ is the angle between the c-axis of the crystal and the direction of diffusion, and $D_{\mathrm{Fe}}^{*}(\theta), D_{\mathrm{Fe}(\mathrm{c})}^{*}$, and $D_{\mathrm{Fe}(\mathrm{a})}^{*}$ are the self-diffusivities of iron atoms along the diffusion direction $(\theta)$, c-axis, and a-axis, respectively.

According to the result after Birchenall ${ }^{(2)}$, the
Table 1 X-ray diffraction patterns, inclination angles of c-axis and the calculated correction factors, where italic types show the most strong peaks for $(h k l)$ and the mean values for $\theta$ and correction factor.

\begin{tabular}{lcrc}
\hline \hline Exp. conditions & $(h k l)$ & Degrees, $\theta$ & $\left(1-0.5 \cdot \sin ^{2} \theta\right)$ \\
\hline 760mmHg,30min (001),(002),(004) & $0 \sim 10,6$ & $1.000 \sim 0.985,0.995$ \\
$76 \mathrm{mmHg}, 40 \min (102),(103),(104)$ & $20 \sim 40,31$ & $0.941 \sim 0.794,0.867$ \\
$7.6 \mathrm{mmHg}, 90 \mathrm{~min}(101),(102)$ & $30 \sim 50,40$ & $0.875 \sim 0.706,0.794$ \\
\hline
\end{tabular}

$D_{\mathrm{Fe}(\text { c) }}^{*}$ is about twice as large as the $D_{\mathrm{Fe}(\text { a) }}^{*}$ at $700^{\circ} \mathrm{C}$, independent of the defect concentration in the sulfide. Thus, substituting $D_{\mathrm{Fe}(\mathrm{c})}^{*}=2 \cdot D_{\mathrm{Fe}(\mathrm{a})}^{*}$ in eq. (1),

$$
D_{\mathrm{Fe}}^{*}(\theta)=D_{\mathrm{Fe}(\mathrm{c})}^{*} \cdot\left(1-0.5 \cdot \sin ^{2} \theta\right) \text {. }
$$

Here, the term $\left(1-0.5 \cdot \sin ^{2} \theta\right)$ could be regarded as the correction factor for the case $\theta \neq 0$. The correction factor as well as $(h k l)$ planes determined by X-ray diffraction are shown in Table 1.

On the other hand, according to Wagner's theory ${ }^{(4)}$ on the scaling process of the electronic conductor the rational rate constant $\left(K_{r}\right)$ is approximately given by the following equation:

$$
K_{r}=C \cdot\left(D_{\mathrm{Fe}_{\mathrm{e}}}^{*}\right)_{\mathrm{s}} \cdot\left(\mathrm{P}_{\mathrm{S}_{2}}\right)^{1 / n},
$$

where $\left(D_{\mathrm{Fe}}^{*}\right)_{\mathrm{s}}$ is the self-diffusivity of iron ions under the standard state of $1 \mathrm{~atm}$ of sulfur pressure, and $C$ is a constant. By assuming that the self-diffusivity of iron ions $\left(D_{\mathrm{Fe}}^{*}\right)$ under a given sulfur pressure is proportional to the vacancy concentration $\left(V_{\mathrm{Fe}}\right)$ in the iron sulfide, that is, $D_{\mathrm{Fe}}^{*} \propto\left(V_{\mathrm{Fe}}\right),\left(D_{\mathrm{Fe}}^{*}\right)_{\mathrm{s}} \cdot\left(\mathrm{P}_{\mathrm{S}_{2}}\right)^{1 / n}=$ $C^{\prime} \cdot\left(V_{\mathrm{Fe}}\right)$, because $D_{\mathrm{Fe}}^{*}=\left(D_{\mathrm{Fe}}^{*}\right)_{\mathrm{s}} \cdot\left(P_{\mathrm{S}_{2}}\right)^{1 / n}$, where $C^{\prime}$ is a constant. Accordingly, eq. (3-1) is given as

$$
K_{\mathrm{r}}=C^{\prime \prime} \cdot\left(V_{\mathrm{Fe}}\right),
$$

where $C^{\prime \prime}$ is a constant. Therefore, under a constant sulfur pressure the rational rate constant is proportional to the self-diffusivity of iron and the vacancy concentration.

The rate constant $\left(K_{r \text { (cal.) }}\right)$ which is equal to the value along the c-axis of the ferrous sulfide crystal is expressed by

$$
K_{r(\text { cal. })}=K_{r(\text { obs. })} /\left(1-0.5 \cdot \sin ^{2} \theta\right),
$$




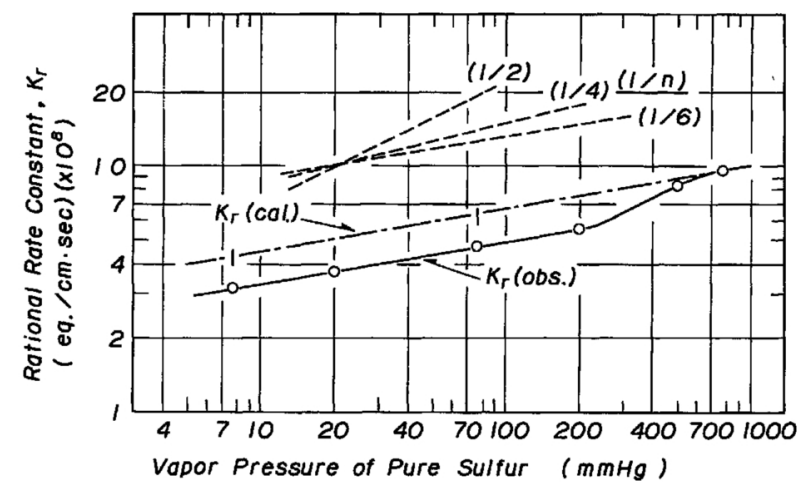

Fig. 4 Comparison of observed values and calculated ones from eq. (4). Broken lines show the slopes with various $1 / n$ values.

where $K_{r(\text { obs. })}$ is the observed rate constant under various sulfur pressures.

Figure 4 shows the relationships between $K_{r(\mathrm{cal} .)}$ or $K_{r(\text { obs.) }}$ and sulfur pressure, and the slopes of $1 / 6,1 / 4$, and also $1 / 2$, meanings of which will be explained later, are shown in broken lines, respectively, for comparison. From this figure it is shown that the relationship between the logarithm of $K_{r(\text { cal.) }}$ besides $K_{r(\text { obs.) }}$ and the logarithm of sulfur pressure is linear and the slope is $1 / 5.7$, that is, $K_{r}=3 \cdot 10^{-8} \cdot\left(P_{\mathrm{S}_{2}}\right)^{1 / 5.7}$.

Next, from the sulfur pressure dependence on the scaling rate constant the electronic and lattice defects of the ferrous sulfide are considered as follows:

This sulfide is a metal deficit p-type semiconductor, in which the sulfur sublattice is perfect, while the iron sublattice has many vacancies. Further, there are electronic defects such as positive holes corresponding to the vacancy formation.

These defective structures will be shown as following equations:

$$
\begin{aligned}
& 1 / 2 \mathrm{~S}_{2} \rightleftarrows \mathrm{S} \rightleftarrows V_{\mathrm{Fe}}^{\prime \prime}+\mathrm{FeS}+2 \oplus \\
& 1 / 2 \mathrm{~S}_{2} \rightleftarrows \mathrm{S} \rightleftarrows V_{\mathrm{Fe}}^{\prime}+\mathrm{FeS}+\oplus \\
& 1 / 2 \mathrm{~S}_{2} \rightleftarrows \mathrm{S} \rightleftarrows V_{\mathrm{Fe}}^{\circ}+\mathrm{FeS},
\end{aligned}
$$

where $\oplus$ is a positive hole and $V_{\mathrm{Fe}}^{\prime \prime}, V_{\mathrm{Fe}}^{\prime}$, and $V_{\mathrm{Fe}}^{\mathrm{o}}$ are the doubly ionized, singly ionized, and neutral vacancies, respectively. Applying the mass action law to the above relations and taking into account the electroneutrality condition and after rearrangement, the relationships are shown in the next forms:

$$
\begin{aligned}
& \left(V_{\mathrm{Fe}}^{\prime \prime}\right)=K_{1} \cdot\left(P_{\mathrm{S}_{2}}\right)^{1 / 6} \\
& \left(V_{\mathrm{Fe}}^{\prime}\right)=K_{2} \cdot\left(P_{\mathrm{S}_{2}}\right)^{1 / 4} \\
& \left(V_{\mathrm{Fe}}^{\circ}\right)=K_{3} \cdot\left(P_{\mathrm{S}_{2}}\right)^{1 / 2},
\end{aligned}
$$

where parentheses in the equations mean concentration of iron vacancy. $K_{1}, K_{2}$, and $K_{3}$ are constant, respectively.

Considering the relationships between $K_{r}$ and $P_{\mathrm{S}_{2}}{ }^{1 / n}$ in eq. (3-1), and also between $K_{r},\left(V_{\mathrm{Fe}}\right)$, and $P_{\mathrm{S}_{2}}{ }^{1 / n}$ obtained from eqs. (3-2) and (6),

$$
\begin{array}{ll}
1 / n=1 / 6 & \text { for eq. }(5-1) \\
1 / n=1 / 4 & \text { for eq. }(5-2) \\
1 / n=1 / 2 & \text { for eq. }(5-3) .
\end{array}
$$

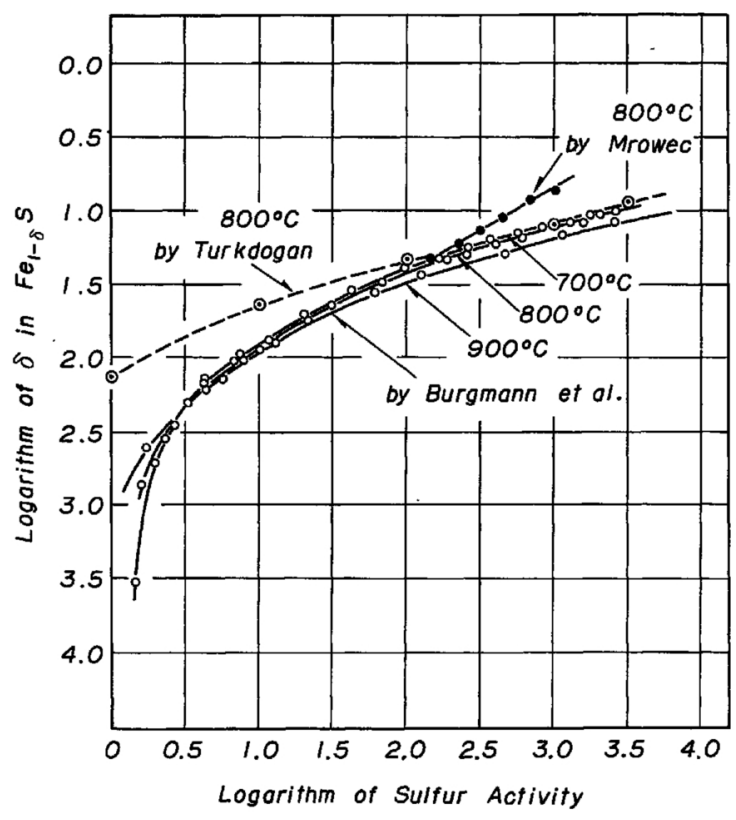

Fig. 5 Dependence of lattice defect concentrations upon sulfur activities.

Within the experimental errors the value $1 / n=1 / 5.7$ shown in Fig. 4 seems to be in good agreement with the value in eq. (7-1), so that the defect structure of the ferrous sulfide will be that suggested by eq. (5-1).

Similar results will be discussed from the relationship between the vacancy concentration and sulfur pressure determined by the thermodynamical study. These relationships were reported by Burgmann ${ }^{(5)}$, Turkdogan $^{(6)}$, and also calculated by Mrowec ${ }^{(7)}$ using Rosenqvist's data ${ }^{(8)}$, and are shown in Fig. 5. In this figure it seems that the double logarithmic relationships between vacancy concentration and sulfur activity are linear in the range of high sulfur activity. Using the relation: $a_{\mathrm{s}}=\left(\mathrm{P}_{\mathrm{S}_{2}}\right)^{1 / 2}$, the slopes of these relationships besides Mrowec's one are very close to $1 / 6$. Accordingly, the eq. (5-1) as well as (7-1) are valid for the ferrous sulfide under a higher sulfur pressure as in the present investigation.

From these results it seems that there is no interaction between vacancies and positive holes.

Recently, Vaugham et al. ${ }^{(9)}$ have reported the results of the Mössbauer measurement at $77^{\circ} \mathrm{K}$ on the pyrrhotite having the composition of $\mathrm{Fe}_{7} \mathrm{~S}_{8}$. Their results support the crystal structures suggested by Bertaut ${ }^{(10)}$. Further, for the electronic state in the sulfide Goncharov et al. ${ }^{(11)}$ reported that the electroneutrality in the ferrous sulfide with various non-stoichiometric compositions is held by means of the valence increase of sulfur ions and that the ionic bonding in the sulfide is about $53 \%$. From these experimental results it is considered that the concentration of the positive hole will decrease considerably, resulting in an increase of the $1 / n$ value. These results seem to be very different from the present results. The reason of this disagreement is not clear, although it must be taken into consideration that the present kinetic investigation and the thermodynamical studies ${ }^{(5) \sim(8)}$ are carried out at elevated temperatures, whereas the Mössbauer measurements 
sited above $\mathrm{e}^{(9)(11)}$ are carried out at room temperature or $77^{\circ} \mathrm{K}$. Therefore, there may be a considerable difference in the electronic state with the change in temperature. Accordingly, in order to elucidate the lattice defects and the electronic states in the ferrous sulfide the Mössbauer measurement will be desired to carry out at high temperature.

Finally, it is worthwhile to note that in connection of Wagner's theory ${ }^{(4)}$ with defective structures, the crystalline anisotropic properties for diffusion and other properties will have to be considered carefully.

\section{Conclusion}

The preferred orientation of the ferrous sulfide crystal in the scale formed on pure iron at $700^{\circ} \mathrm{C}$ and the orientation change with sulfur pressure were determined quantitatively by means of the pole figure analyzer.

By use of the results obtained and the informations on the iron self-diffusivity for an anisotropic ferrous sulfide crystal, the effect of the preferred orientation of the crystal on the overall corrosion rates was clarified.

The dependence of the scaling rate of iron on sulfur pressure based on the double logarithmic expression can be described by the following equation: $K_{r}=$ $3 \times 10^{-8} \cdot\left(P_{S_{2}}\right)^{1 / 5.7}$, suggesting no interaction be- tween the vacancies and positive holes.

\section{Acknowledgments}

The present authors wish to express their hearty thanks to Tokyo Shibaura Electric Co., Ltd. for kind permission to use the modified X-ray Direct Pole Figure Analyzer, and also to Ishikawajima-Harima Heavy Industry Ltd. for preparing high purity iron sheets.

\section{REFERENCES}

(1) T. Narita and K. Nishida: Trans. JIM, 14 (1973), 439.

(2) C. E. Birchenall: private communication (1961).

(3) P. G. Shewmon: Diffusion in Solids, McGraw-Hill Book Co., New York, (1963), p. 36.

(4) C. Wagner: Atom Movements, ASM, Cleveland, Ohio, (1951), p. 153.

(5) W. Burgmann, G. Urbain, and M. G. Frohberg: Rev. Metallurg., 55 (1968), 567.

(6) E. T. Turkdogan: Trans. Met. Soc. AIME, 242 (1968), 1665.

(7) S. Mrowec: Bull. Acad. Poland, ser. sci. chim., 15 (1967), 517.

(8) T. Rosenquist: J. Iron Steel Inst. (London), 176 (1954), 37.

(9) D. J. Vaugham and M. S. Ridout: Solid State Commun., 8 (1970), 2165

(10) E. F. Bertaut: Acta Cryst., 6 (1953), 557.

(11) G. N. Goncharov, Yu. M. Ostanevich, S. B. Tomilov, and L. Cser: Phys. Status Solidi, 37 (1970), 141. 